\title{
Occurrence of Nonarticular Incidental Findings on Panoramic Radiographs in Painful Temporomandibular Disorders
}

\author{
Ocurrencia de Hallazgos Incidentales no Articulares en Ortopantomografias \\ en los Trastornos Temporomandibulares Dolorosos
}

\author{
Liz Anne G. Vaiciulis'; Samantha Christine X. B. Cavalcanti'; Israel Chilvarquer² \& João Gualberto C. Luz'
}

VAICIULIS, L. A. G.; CAVALCANTI, S. C. X. B.; CHILVARQUER, I. \& LUZ, J. G. C. Occurrence of nonarticular incidental findings on panoramic radiographs in painful temporomandibular disorders. Int. J. Odontostomat., 14(2):213-219, 2020.

\begin{abstract}
Facial pain is one of the symptoms of temporomandibular disorders (TMDs) but can be associated with other pathological conditions. The present study retrospectively evaluated the occurrence of nonarticular incidental findings in panoramic radiographs in a group of patients with painful TMDs. Outpatients with a diagnosis of TMD were included and distributed into three groups: arthralgia, myalgia or arthralgia and myalgia, according to the Diagnostic Criteria for Temporomandibular Disorders (DC/TMD). Nonarticular incidental findings of their panoramic radiographs were classified in relation to pathological, dental and endodontic status. The dependency relationships among the variables were analyzed using the likelihood test. Sixty patients (38 women and 22 men; mean age: 36.9 years) were evaluated. There was a predominance of arthralgia plus disc displacement $(43.4 \%)$, followed by myopain plus arthralgia and disc displacement $(38.3 \%)$ and myopain $(18.3 \%)$. Pathologic radiographic changes such as bone loss, caries, maxillary sinus opacification and periapical lesions were frequent. Dental alterations such as the absence and altered position of teeth and impacted teeth were frequent. Endodontic changes such as periapical lesions with or without endodontic treatment were frequent. There was no significant difference between groups except for gyroversion. The incidental findings were compatible with caries, sinusitis, impacted tooth and periapical lesion, which may be associated with orofacial pain and could potentially be superimposed on the initial diagnosis, although this hypothesis was discarded. Findings such as the absence and altered position of teeth were also frequent, which may represent occlusal factors associated with TMDs.
\end{abstract}

KEY WORDS: radiography panoramic, jaw diseases, temporomandibular joint, incidental findings, facial pain.

\section{INTRODUCTION}

Orofacial pain is a common symptom, but its diagnosis is generally considered difficult (Huumonen et al., 2007; Tomoyasu et al., 2014). The number of stomatognathic system structures and their different sources that can produce pain can make the diagnosis of orofacial pain difficult and increase the risk of treatment failure (Okeson, 2008). A review of a series of patients with persistent orofacial pain revealed many diagnoses, mainly temporomandibular disorders (TMDs), pulpitis and trigeminal neuralgia (Siqueira et al., 2004). A study of dental patients with orofacial pain showed that they received diagnoses other than the initial diagnosis, such as neuropathic pain, myofascial pain and psychogenic pain (Tomoyasu et al.). An epidemiological study of facial pain and TMDs demonstrated that facial pain is a usual symptom in the adult population and has an association with TMDs as well as with other musculoskeletal pain symptoms, while trauma to the face, certain occlusal factors and dental pathology may have a role in the etiology (Rauhala et al., 2000). There are few reports on the clinical observation of patients with orofacial pain (Tomoyasu et al.).

In the clinical evaluation of patients with orofacial pain, panoramic radiography is used to screen and exclude pathology in the bony structures of the jaw and teeth (Tomoyasu et al.), while computed

\footnotetext{
1 Department of Oral and Maxillofacial Surgery, School of Dentistry, University of São Paulo, Brazil

2 Department of Stomatology, Division of Radiology, School of Dentistry, University of São Paulo, Brazil

FUNDING SOURCES: No external funding, apart from the support of the authors' institution, was available for this study.
} 
tomography and magnetic resonance imaging are used to evaluate the hard and soft tissues of the temporomandibular joint (Brooks et al., 1997).

Panoramic radiographs are useful for diagnosing teeth with clinical suspicion of periapical pathologic conditions, the presence of partially erupted teeth, clinically evident caries lesions, swelling, and clinically suspected unerupted teeth (Rushton et al., 2002). Notably, intraoral films are of greater diagnostic aid in these pathological alterations (Rushton \& Rushton, 2012). Other pathological jaw changes, such as periodontal horizontal or vertical bony loss, rarefaction or bone condensation, tumor aspect and calcification of the stylohyoid ligament, can be evidenced by panoramic radiography (Luz et al., 2003; Huumonen et al.; Araujo et al., 2016). In addition, panoramic radiography provides the most information on the maxillary sinus, and it may be an adequate imagingmethod (Malina-Altzinger et al., 2015). Panoramic radiography is considered as an excellent diagnostic tool for the identification of mucosal thickening and mucosal cysts (Mathew et al., 2009).

An incidental finding is one that is unrelated to the present illness and is discovered unintentionally. The purpose of the present study was to retrospectively evaluate the occurrence of nonarticular incidental findings in panoramic radiographs of a group of patients with painful TMDs.

\section{MATERIAL AND METHOD}

Data from outpatients who had been diagnosed with TMDs, were referred to the Temporomandibular Disorders and Orofacial Pain Clinic of the Oral and Maxillofacial Surgery Department within two years, and were equal to or greater than 18 years old were included regardless of their gender, race and social status. This sample constituted patients from the study cases of another study (de Carvalho et al., 2018); this was a retrospective study. No patient was asked to return for further evaluation. The patients came from public dental or medical health services with a diagnosis of TMD that was provisional and previously determined TMD. TMDs were diagnosed based on the chief complaints presented by the patients and a clinical examination that was conducted according to the Diagnostic Criteria for Temporomandibular Disorders (DC/TMD) (Schiffman et al., 2014). The examinations were supervised by the fourth author who is an experienced clinician. The TMD diagnosis was established using the DC/TMD diagnostic decision tree, the completed clinical examination form and the symptom questionnaire. The patients who presented with previous orthodontic treatment, maxillofacial trauma, orthognathic or temporomandibular joint surgeries, fibromyalgia syndrome, neurological disorders or congenital craniofacial abnormalities, as well those without pain symptomatology or whose panoramic radiographs were unavailable, were excluded from the study. Data from the clinical examination were obtained from the previous study. Ethical approval for this study (Protocol CAAE 36601914.0.0000.0075) was provided by the Research Ethics Committee.

All of the panoramic images were made at the same radiological facility using a Panex EC Veraview (J Morita Corp, Kioto, Japan) at 70-90 kV and $10 \mathrm{~mA}$. The panoramic radiographs were analyzed separately under standard conditions by the third and fourth authors. No panoramic radiographs were made during this study. The radiographic aspects were divided into pathological, dental and endodontic status. The following pathological findings were evaluated: dentinal caries considered on the basis of the clinical record; horizontal bone loss when parallel to the amelocementary limit; vertical bone loss when in the angular, oblique direction beginning at the lateral portion of the alveolar crest; periapical lesion; alterations in the maxillary sinus including membrane thickening, opacification and mucosal cyst; calcification of the stylohyoid ligament represented by the increase in length of the styloid process; palatine cleft; rarefaction or bone condensation; and tumor finding (Rushton et al.; Luz et al., 2003; Huumonen et al.; Mathew et al.; Rushton \& Rushton; Malina-Altzinger et al.). The following dental statuses were evaluated: partially erupted and nonerupted teeth, impacted tooth, absent teeth, extrusion, intrusion, mesialization and distalization of the teeth adjacent to a tooth absence, gyroversion, migration or transposition, lack of space or dental crowding, macrodontia or microdontia, anodontia, supernumerary teeth, incisal or occlusal wear, crown or root fracture, root remnants and dental implant. The dental implant, because it is a prosthetic piece installed in the location of an absent tooth, was not considered dental absence. If there was anodontia, it was recorded as dental absence (Huumonen et al.). The following endodontic/periapical statuses were evaluated: periapical lesion without endodontic treatment, endodontic treatment without or with a periapical lesion, being circumscribed or diffuse in appearance (Huumonen et al.). 
The data were tabulated and submitted for statistical analysis. The likelihood ratio test was applied to verify possible differences between the three groups studied when compared concomitantly for the varia- bles of interest. The statistical package IBM SPSS(Statistical Package for Social Sciences), version 23.0, was used to obtain the results. The level of significance was set at $5 \%(p \leq 0.050)$.
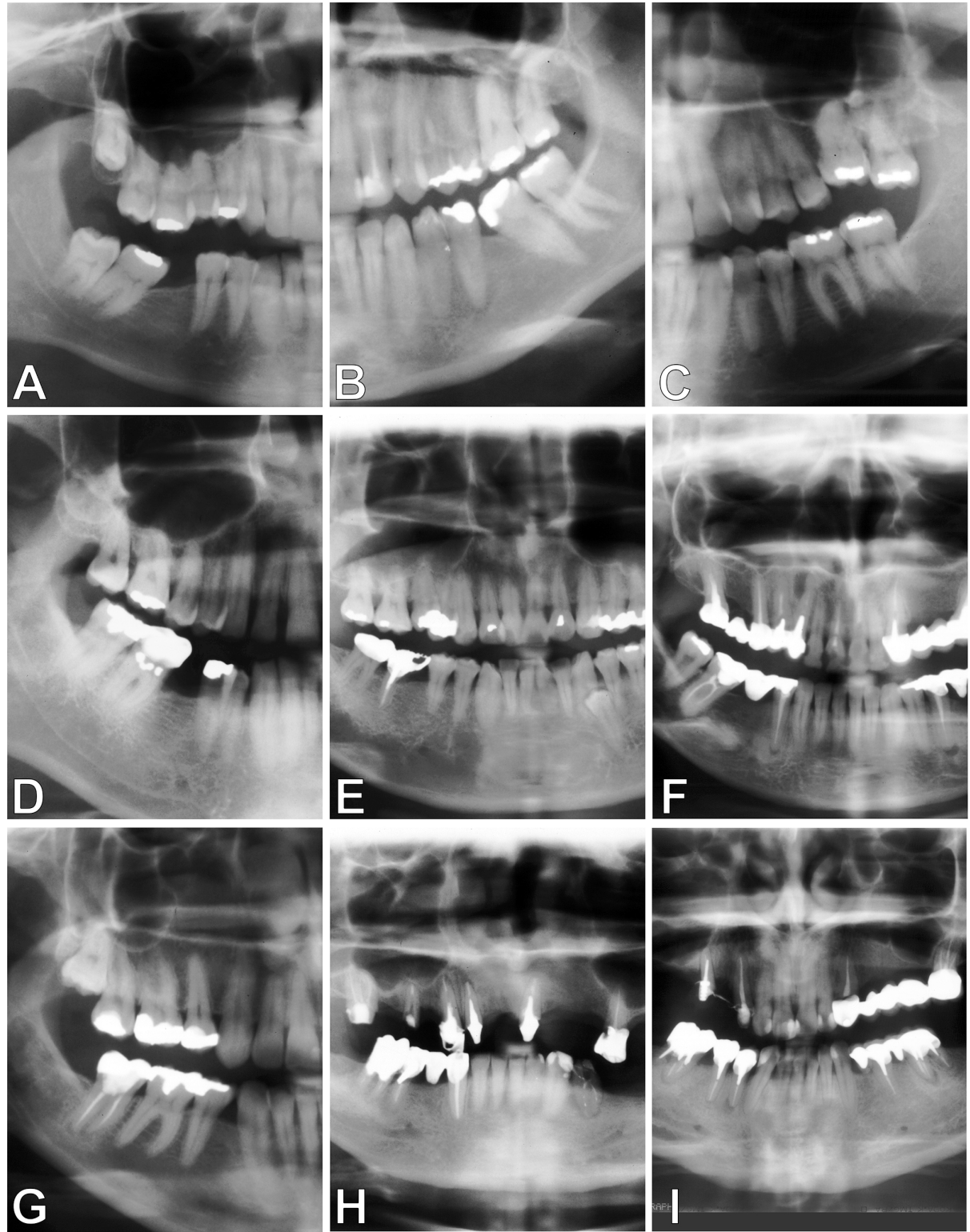

Fig. 1. Panoramic radiograph images. (A) Case \# 25 = Tooth 18 impacted, dental absence of 46, mesialization of teeth adjacent to tooth loss; (B) Case \# 55 = Gyroversion of teeth 33 and 34; (C) Case \# 48 = Intrusion of tooth 26, crowding of left posterior superior teeth; (D) Case \# 50 = Horizontal and vertical bone loss, radiolucent image on crown of tooth 46, incisal wear on anterior teeth; (E) Case \# 45 = Opacification of the right maxillary sinus, tooth 34 impacted; (F) Case \# 18 = Teeth 35 and 44 with endodontic treatment with diffuse periapical lesion, tooth 13 with endodontic treatment with circumscribed periapical lesion; (G) Case \# 47 = Tooth 47 with endodontic treatment with diffuse periapical lesion, opacification of the right maxillary sinus, tooth 18 impacted, horizontal and vertical bone loss; $(\mathrm{H})$ Case \# 46 = Teeth 12, 13 and 15 with endodontic treatment with diffuse periapical lesion, tooth 43 with endodontic treatment without periapical lesion, opacification of the right maxillary sinus. (I) Case \# 58 = Tooth 22 with circumscribed periapical bone rarefaction, teeth 37 and 44 with endodontic treatment with circumscribed periapical lesion.

\section{RESULTS}

Data from sixty patients (38 women and 22 men; mean age: 36.9 years) who were selected from 80 consecutive patients with TMDs were evaluated. There was a predominance of arthralgia plus disc displacement (ADD) (43.4 $\%)$, which was followed by myopain plus arthralgia and disc displacement (MADD) $(38.3 \%)$ and latter myopain (M) $(18.3 \%)$ groups. The mean ages were 37.6 years in the myopain group, 37.7 years in the arthralgia plus disc displacement group and 35.7 years in the myopain plus arthralgia and disc displacement group; there was no significant difference between the groups with the use of the Kruskal Wallis test $(p=0.845)$. The female gender was more frequent in the myopain (63.3\%), arthralgia plus disc displacement $(73.1 \%)$ and myopain plus arthralgia and disc displacement (52.2\%) groups, and there was no significant difference among the groups when applying the likelihood ratio test $(p=$ $0.317)$. The main nonarticular incidental findings in panoramic radiographs of this study are shown in Figure 1.

$\mathrm{P}$ a thologic a I radiographic abnormalities were observed and are listed 
VAICIULIS, L. A. G.; CAVALCANTI, S. C. X. B.; CHILVARQUER, I. \& LUZ, J. G. C. Occurrence of nonarticular incidental findings on panoramic radiographs in painful temporomandibular disorders. Int. J. Odontostomat., 14(2):213-219, 2020.

in descending order: horizontal bone loss $(n=53,88.3$ $\%)$, caries $(n=50,83.3 \%)$, maxillary sinus opacification $(n=40,66.7 \%)$, vertical bone loss $(n=29,48.3 \%)$, periapical lesion ( $n=24,40 \%$ ), calcification of the stylohyoid ligament $(n=7,11.7 \%)$, and mucous cyst of the maxillary sinus $(n=4,6.7 \%)$. There were no patients who had palatine clefts, rarefaction or bone condensation or tumor findings. With the application of the likelihood ratio test, there was no significant difference between the groups. The distribution of pathological findings associated with each group is shown in Table I.

Dental radiographic changes were observed and are listed in descending order: missing teeth $(n=56$, $93.3 \%)$, mesialization/distalization ( $n=31,51.7 \%)$, gyroversion ( $\mathrm{n}=10,16.7 \%)$, extrusion/intrusion $(\mathrm{n}=$ $8,13.3 \%)$, unerupted/partially erupted tooth $(n=5$, $8.3 \%)$, impacted tooth ( $\mathrm{n}=4,6.7 \%)$, migration/ transposition ( $n=4,6.7 \%)$,remaining roots $(n=3,5$ $\%$ ), incisal/occlusal wear $(n=3,5 \%)$, tooth in formation $(n=2,3.3 \%)$, dental crowding $(n=1,1.7 \%)$, supernumerary tooth $(n=1,1.7 \%)$ and dental implant $(n=1,1.7 \%)$. There were no patients who had macrodontia or microdontia or crown or root fractures. With the application of the likelihood ratio test there was a significant difference between the groups only with gyroversion. The distribution of dental findings associated with each group is shown in Table II.

Endodontic/periapical radiographic changes were observed and are listed in descending order:

Table I. Cross-tabulation of the occurrence of pathological abnormalities on panoramic radiographs associated with each group and significance of the likelihood ratio test $[\mathrm{n}(\%)]$.

\begin{tabular}{|c|c|c|c|c|c|c|c|}
\hline \multirow{2}{*}{ Panoramic findings } & \multicolumn{2}{|c|}{ M } & \multicolumn{2}{|c|}{ ADD } & \multicolumn{2}{|c|}{ MADD } & \multirow{2}{*}{$\begin{array}{c}p \\
\text { value }\end{array}$} \\
\hline & Present & Absent & Present & Absent & Present & Absent & \\
\hline Horizontal bone loss & $11(100.0)$ & $0(0.0)$ & $22(84.6)$ & $4(15.4)$ & $20(87.0)$ & $3(13.0)$ & 0.398 \\
\hline Caries & $10(90.9)$ & $1(9.1)$ & $23(88.5)$ & $3(11.5)$ & $17(73.9)$ & $6(26.1)$ & 0.299 \\
\hline Maxillary sinus opacification & $7(63.6)^{\prime}$ & $4(36.4)$ & $18(69.2)$ & $8(30.8)$ & $15(65.2)$ & $8(34.8)$ & 0.930 \\
\hline Vertical bone loss & $8(72.7)$ & $3(27.3)$ & $11(42.3)$ & $15(57.7)$ & $10(43.5)$ & $13(56.5)$ & 0.200 \\
\hline Periapical lesion & $4(36.4)$ & $7(63.6)$ & $10(38.5)$ & $16(61.5)$ & $10(43.5)$ & 13(56.5) & 0.904 \\
\hline Calcification of the stylohyoid ligament & $1(9.1)$ & $10(90.9)$ & $4(15.4)$ & $22(84.6)$ & $2(8.7)$ & $21(91.3)$ & 0.735 \\
\hline Mucous cyst of the maxillary sinus & $2(18.2)$ & $9(81.8)$ & $2(7.7)$ & 24(92.3) & $0(0.0)$ & $23(100.0)$ & 0.133 \\
\hline
\end{tabular}

$\mathrm{M}=$ Myopain, $\mathrm{ADD}=$ Arthralgia plus disc displacement, MADD = Myopain plus arthralgia and disc displacement.

Table II. Cross-tabulation of the occurrence of dental changes on panoramic radiographs associated with each group and significance of the likelihood ratio test $[\mathrm{n}(\%)]$.

\begin{tabular}{|c|c|c|c|c|c|c|c|}
\hline \multirow{2}{*}{ Panoramic findings } & \multicolumn{2}{|c|}{ M } & \multicolumn{2}{|c|}{ ADD } & \multicolumn{2}{|c|}{ MADD } & \multirow{2}{*}{$\begin{array}{c}p \\
\text { value }\end{array}$} \\
\hline & Present & Absent & Present & Absent & Present & Absent & \\
\hline Missing teeth & $11(100.0)$ & $0(0.0)$ & $24(92.3)$ & $2(7.7)$ & $21(91.3)$ & $2(8.7)$ & 0.612 \\
\hline Mesialization/Distalization & $6(54.5)$ & $5(45.5)$ & $14(53.8)$ & $12(46.2)$ & $11(47.8)$ & $12(52.2)$ & 0.895 \\
\hline Gyroversion & $0(0.0)$ & $11(100.0)$ & $8(30.8)$ & $18(69.2)$ & $2(8.7)$ & $21(91.3)$ & 0.031 \\
\hline Extrusion/Intrusion & $1(9.1)$ & $10(90.9)$ & $2(7.7)$ & $24(92.3)$ & $5(21.7)$ & $18(78.3)$ & 0.318 \\
\hline Unerupted/Partially erupted tooth & $1(9.1)$ & $10(90.9)$ & $3(11.5)$ & $23(88.5)$ & $1(4.3)$ & $22(95.7)$ & 0.658 \\
\hline Impacted tooth & $2(18.2)$ & $9(81.8)$ & $1(3.8)$ & $25(96.2)$ & $1(4.3)$ & $22(95.7)$ & 0.237 \\
\hline Migration/Transposition & $0(0.0)$ & $11(100.0)$ & $2(7.7)$ & 24 (92.3) & $2(8.7)$ & $21(91.3)$ & 0.612 \\
\hline Remaining roots & $1(9.1)$ & $10(90.9)$ & $2(7.7)$ & $24(92.3)$ & $0(0.0)$ & $23(100.0)$ & 0.369 \\
\hline Incisal/Occlusal wear & $0(0.0)$ & $11(100.0)$ & $2(7.7)$ & $24(92.3)$ & $1(4.3)$ & $22(95.7)$ & 0.608 \\
\hline Tooth in formation & $0(0.0)$ & $11(100.0)$ & $1(3.8)$ & $25(96.2)$ & $1(4.3)$ & $22(95.7)$ & 0.789 \\
\hline Dental crowding & $0(0.0)$ & $11(100.0)$ & $1(3.8)$ & $25(96.2)$ & $0(0.0)$ & $23(100.0)$ & 0.514 \\
\hline Supernumerary tooth & $0(0.0)$ & $11(100.0)$ & $0(0.0)$ & $26(100.0)$ & $1(4.3)$ & $22(95.7)$ & 0.441 \\
\hline Dental implant & $0(0.0)$ & $11(100.0)$ & $1(3.8)$ & $25(96.2)$ & $0(0.0)$ & $23(100.0)$ & 0.514 \\
\hline
\end{tabular}

$\mathrm{M}=$ Myopain, $\mathrm{ADD}=$ Arthralgia plus disc displacement, $\mathrm{MADD}=$ Myopain plus arthralgia and disc displacement.

Table III. Cross-tabulation of the occurrence of endodontic/periapical changes on panoramic radiographs associatedwith each group and significance of the likelihood ratio test $[n(\%)]$.

\begin{tabular}{|c|c|c|c|c|c|c|c|}
\hline \multirow{2}{*}{ Panoramic findings } & \multicolumn{2}{|c|}{$\mathrm{M}$} & \multicolumn{2}{|c|}{ ADD } & \multicolumn{2}{|c|}{ MADD } & \multirow{2}{*}{$\begin{array}{c}p \\
\text { value }\end{array}$} \\
\hline & Present & Absent & Present & Absent & Present & Absent & \\
\hline Endodontic treatment without periapical lesion & $4(36.4)$ & $7(63.6)$ & $15(57.7)$ & $11(42.3)$ & $17(73.9)$ & $6(26.1)$ & 0.107 \\
\hline $\begin{array}{l}\text { Endodontic treatment with diffuse periapical } \\
\text { lesion }\end{array}$ & $4(36.4)$ & $7(63.6)$ & $6(23.1)$ & $20(76.9)$ & $5(21.7)$ & $18(78.3)$ & 0.625 \\
\hline Periapical lesion without endodontic treatment & $0(0.0)$ & $11(100.0)$ & $1(3.8)$ & $25(96.2)$ & $3(13.0)$ & $20(87.0)$ & 0.270 \\
\hline $\begin{array}{l}\text { Endodontic treatment with circumscribed } \\
\text { periapical lesion }\end{array}$ & $0(0.0)$ & $11(100.0)$ & $1(3.8)$ & $25(96.2)$ & $2(8.7)$ & $21(91.3)$ & 0.519 \\
\hline
\end{tabular}

$\mathrm{M}=$ Myopain, $\mathrm{ADD}=$ Arthralgia plus disc displacement, $\mathrm{MADD}=$ Myopain plus arthralgia and disc displacement. 
VAICIULIS, L. A. G.; CAVALCANTI, S. C. X. B.; CHILVARQUER, I. \& LUZ, J. G. C. Occurrence of nonarticular incidental findings on panoramic radiographs in painful temporomandibular disorders. Int. J. Odontostomat., 14(2):213-219, 2020.

endodontic treatment without periapical lesion $(n=36$, $60 \%$ ), endodontic treatment with diffuse periapical lesion ( $n=15,25 \%)$, periapical lesion without endodontic treatment $(n=4,6.7 \%)$ and endodontic treatment with circumscribed periapical lesion $(n=3$, $5 \%$ ). With the application of the likelihood ratio test there was no significant difference between the groups. The distribution of endodontic/periapical findings associated with each group is shown in Table III.

\section{DISCUSSION}

The present retrospective study evaluated the occurrence of nonarticular incidental findings in panoramic radiographs, which were represented by pathologic changes, dental status and endodontic/ periapical status, of patients with painful TMDs and possible differences among myopain, arthralgia plus disc displacement and myopain plus arthralgia and disc displacement groups. However, there was no significant difference between groups except for gyroversion.

The personal data presented by the patients in the sample were similar to those described for patients with TMDs. There was a predominance of patients of the female gender and a mean age of 36.9 years, which is in agreement with the literature (Luz et al., 1997; Macfarlane et al., 2002; Schmitter et al., 2004; Gonçalves et al., 2010).

Regarding the pathologic changes, it was observed that many patients presented with horizontal bony loss, caries and maxillary sinus opacification; some presented with vertical bony loss, periapical lesion, and periapical bone rarefaction of diffuse appearance; and a few presented with calcification of the stylohyoid ligament, periapical radiolucency with circumscribed aspect and mucous cyst of the maxillary sinus. Many of these conditions may cause orofacial pain and therefore could potentially be superimposed on the initial diagnosis of TMD. The original diagnoses were obtained with criteria, and such findings would have no association with reported facial pain. When compared to another similar study, all of our findings of pathologic changes were more frequent (Huumonen et al.), which increases the chance of being associated with other possible sources of orofacial pain. Retrospective studies of patients with chronic orofacial pain have found a predominance of diagnoses such as neuropathic pain, myofascial pain, psychogenic pain, odontogenic toothache and others (Siqueira et al.; Tomoyasu et al.). It was demonstrated that the original diagnosis was incorrect or incomplete in many cases, but the follow-up of the patients after receiving the respective therapy indicated relief of pain (Siqueira et al.; Tomoyasu et al.).

Odontogenic pain may range from hypersensitivity to spontaneous, intense and diffuse pain (Zero et al., 2011). The possibility of diagnoses associated with odontogenic pain, such as caries, pulp and periapical diseases, may complicate the diagnosis (Zero et al.; Halpern \& Willis, 2016). Studies have referred to pain of dental origin as odontalgia or pulpitis, both associated with the presence of caries. A correlation between caries experience and the prevalence of toothache has been described (Slade, 2001). Dental pain reflects the severity of dental caries (de Lacerda et al., 2004) and the number of decayed teeth is associated with dental pain (Santiago et al., 2013). The location of orofacial pain from odontogenic toothache has been reported as in the jaws (Tomoyasu et al.). A population study on the characteristics of toothache showed a predominance of moderate and intermittent pain and self-medication for pain control being common (Jaiswal et al., 2015).

In our study, the findings of pathological alterations of the paranasal sinuses, in the form of maxillary sinus opacification and rarely in the form of mucous cysts, were frequent. A study of patients with orofacial pain found some cases with thickening of the maxillary sinus membrane or with mucous cysts; such alterations are generally asymptomatic but may be associated with several symptoms, such as facial pain (Huumonen et al.). Symptoms such as headaches and facial pain are frequent in maxillary sinusitis (Songes et al., 2014). A panoramic radiograph may show mucosal thickening or fluid in the lower part of the maxillary sinus, presenting as radiopaque areas relative to the contralateral side (Ferguson, 2014). Distinguishing between odontogenic orofacial pain and pain associated with maxillary sinusitis is important to prevent unnecessary dental intervention and to direct patients for the correct treatment (Ferguson). A frequent association between odontogenic infections and unilateral sinus opacification has been described (Matsumoto et al., 2015).

There were also frequent findings such as missing teeth, and associated changes, such as mesialization, gyroversion and extrusion, in this study. These findings may represent occlusal factors associated with the etiology or worsening of temporomandibular disorders. It has been demonstrated that individuals with missing posterior teeth have a higher prevalence of TMDs (Wang et al., 2009). A positive association of posterior 
mandibular missing teeth with the presence of intraarticular TMDs (Tallents et al., 2002) and the presence of muscle pain has been reported (Teixeira et al., 2007). Although the importance of occlusal treatment of TMD problems is recognized, the relationship is controversial because occlusion is not strictly demonstrated and is not considered the dominant cause of TMD problems (Badel et al., 2012). It is interesting to note that multiple dental absences were associated with the intensity of dental pain due to caries in an adult population with precarious social conditions and a low level of schooling (de Lacerda et al.). In our study, some of the patients presented unerupted/partially erupted and impacted teeth. A study showed that many cases of impacted mandibular third molars had symptoms of pain (Obiechina et al., 2001). Pain and pericoronitis are the most common symptoms usually associated with third molars, with the level of the occlusal plane at the same level as the occlusal plane of second molar impaction and vertical position (Yilmaz et al., 2016).

Among the endodontic and periapical findings, endodontic treatment with periapical lesions of diffuse appearance was frequent. A study on the histopathology of radiolucent jaw lesions showed that radiolucent inflammatory jaw lesions were predominantly periapical granulomas (Becconsall-Ryan et al., 2010). Asymptomatic apical periodontitis presents periapical radiolucency, no response to pulp vitality tests, and no response to percussion or palpation within normal limits (Zero et al.). The odontogenic pain arises from mechanical nociceptive stimuli and by the release of inflammatory chemical mediators (Okeson). The presence of inflammatory chemical mediators due to apical periodontitis may progress to painful symptomatology and even swelling without radiographic changes. Swelling and pain are the most frequent clinical signs and symptoms of jaw lesions (Araujo et al.). A study on pain levels and symptoms of acute dental pain found pulpitis and apical periodontitis to be severely painful and that the best indicator for the latter was the absence of pain to cold stimuli (Rechenberg et al., 2016). Another study on persistent pain at 6 months after root canal treatment observed a predominance of nonodontogenic pain, with TMDs being the most frequent (Nixdorf et al., 2015). Pulpalgia may cause symptoms that mimic TMDs or may contribute to TMD signs and symptoms (Wright, 2008).

The occurrence of nonarticular findings in panoramic radiographs and the symptomatology presented by a group of patients with painful TMDs was evaluated retrospectively. Possible differences among the myopain, arthralgia plus disc displacement and myopain plus arthralgia and disc displacement groups were analyzed, and there was no significant difference between groups except for gyroversion. The findings were compatible with caries, sinusitis, impacted tooth and periapical lesion, which may be associated with orofacial pain and may be superimposed on the initial diagnosis, although this association is not proven. Our findings of pathologic changes were more frequent when compared to those in another similar study (Huumonen et al.). However, there was no relationship between the occurrence of these findings and the original diagnosis of the groups according to $D C / T M D$, and this finding supports that the diagnosis of TMD pain was correct. The professional assistant should be aware that these findings could be superimposed on the initial diagnosis. Additionally, findings such as the absence and altered position of teeth were also frequent, which may represent occlusal factors associated with TMDs.

VAICIULIS, L. A. G.; CAVALCANTI, S. C. X. B.; CHILVARQUER, I. \& LUZ, J. G. C. Ocurrencia de hallazgos incidentales no articulares en ortopantomografias en los trastornos temporomandibulares dolorosos. Int. J. Odontostomat., 14(2):213-219, 2020.

RESUMEN: El dolor orofacial es uno de los síntomas de los trastornos temporomandibulares (TTM), pero puede estar asociado con otras afecciones patológicas. El presente estudio evaluó retrospectivamente la aparición de hallazgos incidentales no articulares a través de ortopantomografías en un grupo de pacientes con TTM dolorosas. Se incluyeron pacientes con diagnóstico de TTM y se distribuyeron en tres grupos: artralgia, mialgia o artralgia y mialgia, de acuerdo con los criterios de diagnóstico para los trastornos temporomandibulares (DC/TMD). Los hallazgos incidentales no articulares de las ortopantomografias se clasificaron en relación al estado patológico, dental y endodóncico. Las relaciones de dependencia entre las variables se analizaron mediante la prueba de probabilidad. Fueron evaluados 60 pacientes (38 mujeres y 22 hombres; edad media: 36,9 años). Hubo predominio de artralgia más desplazamiento de disco $(43,4 \%)$, seguido de mialgia más artralgia y desplazamiento de disco (38,3\%) y mialgia $(18,3 \%)$. Las alteraciones radiográficas patológicas como pérdida ósea, carie dentaria, opacificación del seno maxilar y lesiones periapicales fueron frecuentes. Entre las alteraciones dentales, las impactaciones, malposiciones o ausencias dentarias fueron frecuentes. Entre las alteraciones endodóncicas, las lesiones periapicales frecuentes. No hubo diferencias significativas entre los grupos, excepto para la girosversión dentaria. Los hallazgos incidentales fueron compatibles con carie dentaria, sinusitis, diente impactado y lesión periapical, lo que podría estar asociado con el dolor orofacial y así estar sobrepuesto en el diagnóstico inicial, aunque esta hipótesis fue descartada. Hallazgos como la ausencia y la posición alterada de los dientes también fueron frecuentes, lo que puede representar factores oclusales asociados con TTM.

PALABRAS CLAVE: ortopantomografía, enfermedades de la mandíbula, articulación temporomandibular, hallazgos incidentales, dolor facial. 


\section{REFERENCES}

Araujo, J. P.; Lemos, C. A.; Miniello, T. G. \& Alves, F. A. The relevance of clinical and radiographic features of jaw lesions: A prospective study. Braz. Oral Res., 30(1):e96, 2016.

Badel, T.; Marotti, M.; Pavicin, I. S. \& Basic-Kes, V. Temporomandibular disorders and occlusion. Acta Clin. Croat., 51(3):419-24, 2012.

Becconsall-Ryan, K.; Tong, D. \& Love, R. M. Radiolucent inflammatory jaw lesions: a twenty-year analysis. Int. Endod. J., 43(10):859-65, 2010.

Brooks, S. L.; Brand, J. W.; Gibbs, S. J.; Hollender, L.; Lurie, A. G.; Omnell, K. A.; Westesson, P. L. \& White, S. C. Imaging of the temporomandibular joint: a position paper of the American Academy of Oral and Maxillofacial Radiology. Oral Surg. Oral Med. Oral Pathol. Oral Radiol. Endod., 83(5):609-18, 1997.

de Carvalho, E. F.; Chilvarquer, I. \& Luz, J. G. C. Correlations between tomographic findings related to degenerative changes, condylar excursions and position, and pain symptomatology in temporomandibular disorders. J. Orofac. Sci., 10(1):7-13, 2018.

de Lacerda, J. T.; Simionato, E. M.; Peres, K. G.; Peres, M. A.; Traebert, J. \& Marcenes, W. Dental pain as the reason for visiting a dentist in a Brazilian adult population. Rev. Saude Publica, 38(3):453-8, 2004

Ferguson, M. Rhinosinusitis in oral medicine and dentistry. Aust. Dent. J., 59(3):289-95, 2014.

Gonçalves, D. A. G.; Dal Fabbro, A. L.; Campos, J. A. D. B.; Bigal, M. E. \& Speciali, J. G. Symptoms of temporomandibular disorders in the population: an epidemiological study. J. Orofac. Pain, 24(3):270-8, 2010.

Halpern, L. \& Willis, P. Orofacial pain: pharmacologic paradigms for therapeutic intervention. Dent. Clin. North Am., 60(2):381-405, 2016.

Huumonen, S.; Sipilä, K.; Zitting, P. \& Raustia, A. M. Panoramic findings in 34 -year-old subjects with facial pain and pain-free controls. J. Oral Rehabil., 34(6):456-62, 2007.

Jaiswal, A. K.; Pachava, S.; Sanikommu, S.; Rawlani, S. S.; Pydi, S. \& Ghanta, B. Dental pain and self-care: a cross-sectional study of people with low socio-economic status residing in rural India. Int. Dent. J., 65(5):256-60, 2015.

Luz, J. G. C.; Rodrigues, L.; Chilvarquer, I. \& Soler, J. M. P. Mineralization of stylohyoid ligament complex in patients with temporomandibular disorders and asymptomatic individuals: a comparative study. J. Oral Rehabil., 30(9):909-13, 2003.

Luz, J. G.; Maragno, I. C. \& Martin, M. C. Characteristics of chief complaints of patients with temporomandibular disorders in a Brazilian population. J. Oral Rehabil., 24(3):240-3, 1997.

Macfarlane, T. V.; Blinkhorn, A. S.; Davies, R. M.; Kincey, J. \& Worthington, $\mathrm{H}$. V. Oro-facial pain in the community: prevalence and associated impact. Community Dent. Oral Epidemiol., 30(1):52-60, 2002.

Malina-Altzinger, J.; Damerau, G.; Grätz, K. W. \& Stadlinger, P. D. B. Evaluation of the maxillary sinus in panoramic radiography-A comparative study. Int. J. Implant. Dent., 1(1):17, 2015.

Mathew, A. L.; Pai, K. M. \& Sholapurkar, A. A. Maxillary sinus findings in the elderly: a panoramic radiographic study. J. Contemp. Dent. Pract., 10(6):E041-8, 2009.

Matsumoto, Y.; Ikeda, T.; Yokoi, H. \& Kohno, N. Association between odontogenic infections and unilateral sinus opacification. Auris Nasus Larynx, 42(4):288-93, 2015.

Nixdorf, D. R.; Law, A. S.; John, M. T.; Sobieh, R. M.; Kohli, R.; Nguyen, R. H. N. \& National Dental PBRN Collaborative Group. Differential diagnoses for persistent pain after root canal treatment: a study in the National Dental Practice-based Research Network. J. Endod., 41(4):457-63, 2015.

Obiechina, A. E.; Arotiba, J. T. \& Fasola, A. O. Third molar impaction: evaluation of the symptoms and pattern of impaction of mandibular third molar teeth in Nigerians. Odontostomatol. Trop., 24(93):22-5, 2001.

Okeson, J. P. The classification of orofacial pains. Oral Maxillofac. Surg. Clin. North Am., 20(2):133-44, 2008.

Rauhala, K.; Oikarinen, K. S.; Järvelin, M. R. \& Raustia, A. M. Facial pain and temporomandibular disorders: an epidemiological study of the Northern Finland 1966 birth cohort. Cranio, 18(1):40-6, 2000.

Rechenberg, D. K.; Held, U.; Burgstaller, J. M.; Bosch, G. \& Attin, T. Pain levels and typical symptoms of acute endodontic infections: a prospective, observational study. BMC Oral Health, 16:61, 2016.
Rushton, M. N. \& Rushton, V. E. A study to determine the added value of 740 screening panoramic radiographs compared to intraoral radiography in the management of adult ( $>18$ years) dentate patients in a primary care setting. J. Dent., 40(8):661-9, 2012.

Rushton, V. E.; Horner, K. \& Worthington, H. V. Routine panoramic radiography of new adult patients in general dental practice: relevance of diagnostic yield to treatment and identification of radiographic selection criteria. Oral Surg. Oral Med. Oral Pathol. Oral Radiol. Endod., 93(4):488-95, 2002.

Santiago, B. M.; Valença, A. M. G. \& Vettore, M. V. Social capital and dental pain in Brazilian Northeast: a multilevel cross-sectional study. BMC Oral Health, 13:2, 2013.

Schiffman, E.; Ohrbach, R.; Truelove, E.; Look, J.; Anderson, G.; Goulet, J. P.; List, T.; Svensson, P.; Gonzalez, Y.; Lobbezoo, F.; et al. Diagnostic criteria for temporomandibular disorders (DC/TMD) for clinical and research applications: Recommendations of the International RDC/TMD Consortium Network* and Orofacial Pain Special Interest Group. J. Oral Facial Pain Headache, 28(1):6-27, 2014.

Schmitter, M.; Kress, B. \& Rammelsberg, P. Temporomandibular joint pathosis in patients with myofascial pain: a comparative analysis of magnetic resonance imaging and a clinical examination based on a specific set of criteria. Oral Surg. Oral Med. Oral Pathol. Oral Radiol. Endod., 97(3):318-24, 2004

Siqueira, J. T. T.; Lin, H. C.; Nasri, C.; de Siqueira, S. R. D. T.; Teixeira, M. J.; Heir, G. \& Valle, L. B. S. Clinical study of patients with persistent orofacial pain. Arq. Neuropsiquiatr., 62(4):988-96, 2004.

Slade, G. D. Epidemiology of dental pain and dental caries among children and adolescents. Community Dent. Health, 18(4):219-27, 2001.

Songes, G.; Gamerra, M.; Sorrentino, G.; De Luca, R.; Merone, M.; Feleppa, M. \& Bigal, M. E. Endoscopic sinus surgery in individuals with facial pain due to chronic maxillary sinusitis - A functional controlled study. Arq. Neuropsiquiatr., 72(8):609-12, 2014.

Tallents, R. H.; Macher, D. J.; Kyrkanides, S.; Katzberg, R. W. \& Moss, M. $E$. Prevalence of missing posterior teeth and intraarticular temporomandibular disorders. J. Prosthet. Dent., 87(1):45-50, 2002.

Teixeira, A. C. B.; Teixeira, V. C. B. \& Luz, J. G. C. Morphologic malocclusion and signs verified in patients with temporomandibular dysfunctions. $R$. P. G. Rev. Pós-Grad., 14(2):154-9, 2007.

Tomoyasu, Y.; Higuchi, H.; Mori, M.; Takaya, K.; Honda, Y.; Yamane, A.; Yabuki, A.; Hayashi, T.; Ishii-Maruyama, M.; Jinzenji, A.; et al. Chronic orofacial pain in dental patients: retrospective investigation over 12 years. Acta Med. Okayama, 68(5):269-75, 2014

Wang, M. Q.; Xue, F.; He, J. J.; Chen, J. H.; Chen, C. S. \& Raustia, A. Missing posterior teeth and risk of temporomandibular disorders. $J$. Dent. Res., 88(10):942-5, 2009.

Wright, E. F. Pulpalgia contributing to temporomandibular disorder-like pain a literature review and case report. J. Am. Dent. Assoc., 139(4):43640, 2008.

Yilmaz, S.; Adisen, M. Z.; Misirlioglu, M. \& Yorubulut, S. Assessment of third molar impaction pattern and associated clinical symptoms in a Central Anatolian Turkish population. Med. Princ. Pract., 25(2):16975, 2016.

Zero, D. T.; Zandona, A. F.; Vail, M. M. \& Spolnik, K. J. Dental caries and pulpal disease. Dent. Clin. North Am., 55(1):29-46, 2011.

Corresponding author:

João Gualberto C. Luz

Rua Duarte de Azevedo, 284 - cj. 22

02036-021, São Paulo

São Paulo

BRAZIL

Email:jgcluz@usp.br

Received: 15-10-2019

Accepted: 27-12-2019 